\title{
MAPEAMENTO DE UNIDADES MORFOESTRUTURAIS E MORFOESCULTURAIS NO MACIÇO DE MATA GRANDE, ALAGOAS E ENTORNO
}

\author{
Laís Susana de Souza Gois ${ }^{1}$ \\ Nivaneide Alves de Melo Falcão² \\ Kleython de Araújo Monteiro ${ }^{3}$
}

Resumo: A presente artigo teve como objetivo mapear as unidades de morfoestruturas e morfoesculturas, no município alagoano de Mata Grande, aplicando a metodologia sistematizada no Congresso da União Geográfica Internacional em 1968 e editada por Demek em 1972. Foram utilizados dados de estrutura e geologia provenientes da CPRM, lineamentos de relevo, rugosidade de relevo e declividade obtidos através da construção de um Modelo Digital de Elevação, gerado a partir de imagens ALOS com resolução de $12,5 \mathrm{~m}$. Através do mapeamento foram identificadas 11 unidades morfoestruturais, além de unidades morfoesculturais que mostraram-se como ferramentas de base para o planejamento de manejo da áreas que se constitui como cabeceira de drenagem de até 3 bacias hidrográficas são franciscanas. Destaca-se na análise em tela o maciço de Mata Grande como brejo de altitude, possuidor de condições ambientais diferenciadas de seu entorno semiárido.

Palavras-chave: Morfografia. Semiárido. Brejo de altitude.

\section{MAPPING OF MORPHOSTRUCTURAL AND MORPHOSCULPTURAL UNITS IN MATA GRANDE, ALAGOAS AND SURROUNDINGS}

\begin{abstract}
The present research aimed to map the morphostructural and morphosculptural units in the Alagoas municipality of Mata Grande, applying the methodology systematized at the Congress of the International Geographical Union in 1968 and edited by Demek in 1972. Structural and geological data from CPRM were used, as well as structural relief lines, relief roughness, and slope gradient obtained through the construction of a Digital Elevation Model (DEM), generated from ALOS images with $12.5 \mathrm{~m}$ resolution. Through the mapping, 11 morphostructural units were identified, in addition to morphosculptural units that proved itself as a basic tool for the management planning of the area which constitutes the channel heads of 3 franciscan watersheds. The Mata Grande massif stands out as a highland humid enclave (brejo), with different environmental conditions than its semiarid surroundings.
\end{abstract}

Keywords: Morphography. Semiarid. Highland humid enclaves.

\section{MAPEO DE LAS UNIDADES MORFOESTRUCTURALES Y MORFOESCULTURALES EN MATA GRANDE, ALAGOAS Y ALREDEDORES}

Resumen: La presente investigación tuvo como objetivo mapear las unidades morfoestructurales y morfoesculturales en el municipio de Mata Grande, en Alagoas,

\footnotetext{
'Universidade Federal de Pernambuco, Departamento de Ciências Geográficas, Recife, Brasil, laisgois15@gmailcom, http://orcid.org/0000-0003-1787-9819

2Universidade Federal de Alagoas, Instituto de Geografia, Desenvolvimento e Meio Ambiente, Maceió, Brasil,nivaneide.melo@igdema.ufal.br, http://orcid.org/0000-0002-6021-7661

3Universidade Federal de Alagoas, Instituto de Geografia, Desenvolvimento e Meio Ambiente, Maceió, Brasil, kleython.monteiro@igdema.ufal.br, http://orcid.org/0000-0003-4829-3722
} 
aplicando la metodología sistematizada em el Congreso de la Unión Geográfica Internacional en 1968 y editada por Demek en 1972. Se utilizaron datos de estructura y geología de CPRM, así como líneas de relieve, rugosidad de relieve y pendiente obtenidos mediante la construcción de un Modelo Digital de Elevación, generado a partir de imágenes ALOS con una resolución de $12.5 \mathrm{~m}$. A través del mapeo, se identificaron 11 unidades morfoestructurales, además de las unidades morfoesculturales que demostraron ser una herramienta básica para la planificación del manejo del área que constituye las cabezas de los canales de 3 cuencas franciscanas. En el análisis, el macizo de Mata Grande se destaca como un enclave húmedo de las tierras altas (brejo), con diferentes condiciones ambientales que su entorno semiárido.

Palabras clave: Morfografía. Semiárido. Enclave húmedo de las tierras altas.

\section{Introdução}

O relevo é um elemento da paisagem bastante complexo e passível de inúmeras análises que podem ser destinadas de acordo com os processos atuantes em suas respectivas escalas. Dentre essas análises o mapeamento geomorfológico surge como um importante produto, mas também como ponto de partida para outras pesquisas.

O mapeamento de unidades geomorfológicas está diretamente ligado a questões como áreas prioritárias para os mais diferentes tipos de usos da terra, lugares destinados a preservação de relictos e redutos de florísticos e faunísticos, estudos paleoambientais dentre outros. Pois abarca uma quantidade de características morfológicas que dão condições para interpretação de dinâmicas pretéritas ocorridas das determinadas regiões e assim, auxilia na criação de modelos futuros que são pilares do planejamento ambiental.

Devido a esse enorme grau de importância do mapeamento geomorfológico, atualmente, existe uma série de metodologias que seguem recomendações reconhecidas nacional e internacionalmente, além de desenvolvimento de softwares e uma enorme gama de equipamentos para que o resultado seja cada vez mais preciso

Neste trabalho foram adotadas as recomendações da União Geográfica Internacional - UGI que são baseadas em Demek (1972), onde inicialmente deve-se mapear as unidades morfoestruturais, que correspondem aquelas que tem como principais processos atuantes a tectônica e o contexto geológico regional e, posteriormente, as unidades morfoesculturais, com seus principais processos ligados as condições climáticas e à modelagem do relevo.

Foi escolhido para esta pesquisa o maciço de Mata Grande, localizado no Sertão alagoano, caracterizado como brejo de altitude (GOIS, 2020; CAVALCANTI, 2010), 
possuindo características fisiográficas diferentes do seu entorno. Por se tratar de uma área com algumas peculiaridades ambientais em relação ao contexto semiárido, torna-se indispensável a caracterização dos seus atributos físicos. Desta forma, este trabalho busca contribuir para esta caracterização através da determinação de unidades de relevo remotamente discerníveis.

É importante ressaltar que as recomendações de Demek (op cit) abarcam uma longa hierarquia que vai além do mapeamento de unidades morfoestruturais e morfoesculturais, porém que não foram incluídas neste trabalho visto que, para a mesoescala utilizada no mapeamento aqui proposto, as etapas realizadas são suficientes.

\section{Materiais e Métodos \\ Área de estudo}

\section{Localização}

A área de estudo corresponde ao Maciço de Mata Grande e seu entorno, situado no município homônimo (Figura 1), e localizado no extremo NW do Estado de Alagoas. Limita-se a norte com os municípios de Manari e Inajá (PE), a sul com Inhapi e Água Branca, a leste com Canapi e a oeste com Tacaratu (PE) e Água Branca (Figura 1).

Com área de 919,6 km² (3,3\% de AL), inserida na microrregião Serrana do Sertão Alagoano, o município de Mata Grande encontra-se nas coordenadas geográficas de $9^{\circ} 07^{\prime} 06^{\prime \prime}$ de latitude sul e $37^{\circ} 44^{\prime} 04^{\prime \prime}$ de longitude oeste.

Figura 1- Localização do Maciço de Mata Grande, Alagoas,

\section{Brasil}

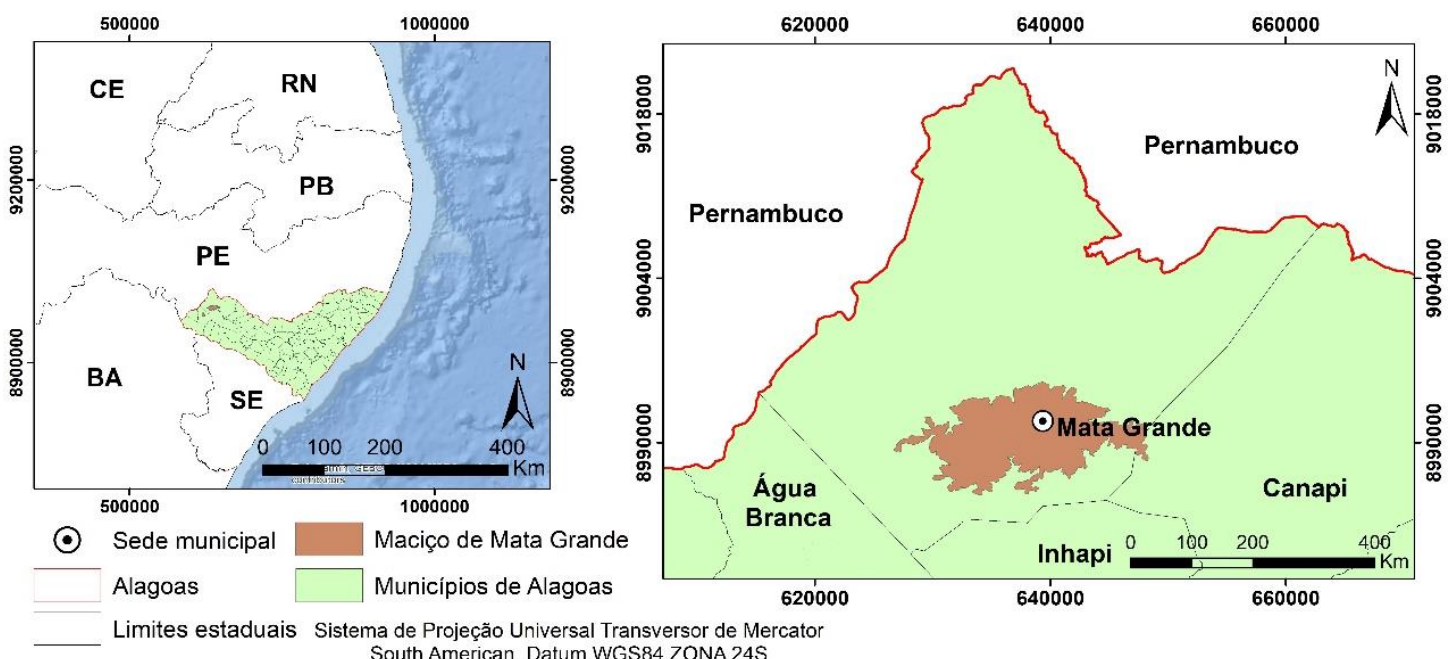


O município encontra-se geologicamente inserido na Província Borborema, representada pelos litótipos dos complexos Cabrobó, Belém do São Francisco e Riacho da Barreira (Suíte Chorrochó), Suíte Intrusiva Shoshonítica Salgueiro/Terra Nova, formações Tacaratu e Inajá, além de depósitos colúvio-eluviais (Figura 2). Todas essas unidades são resultantes de 4 principais momentos, distribuídos ao longo do tempo geológico.

Figura 2- Geologia da área

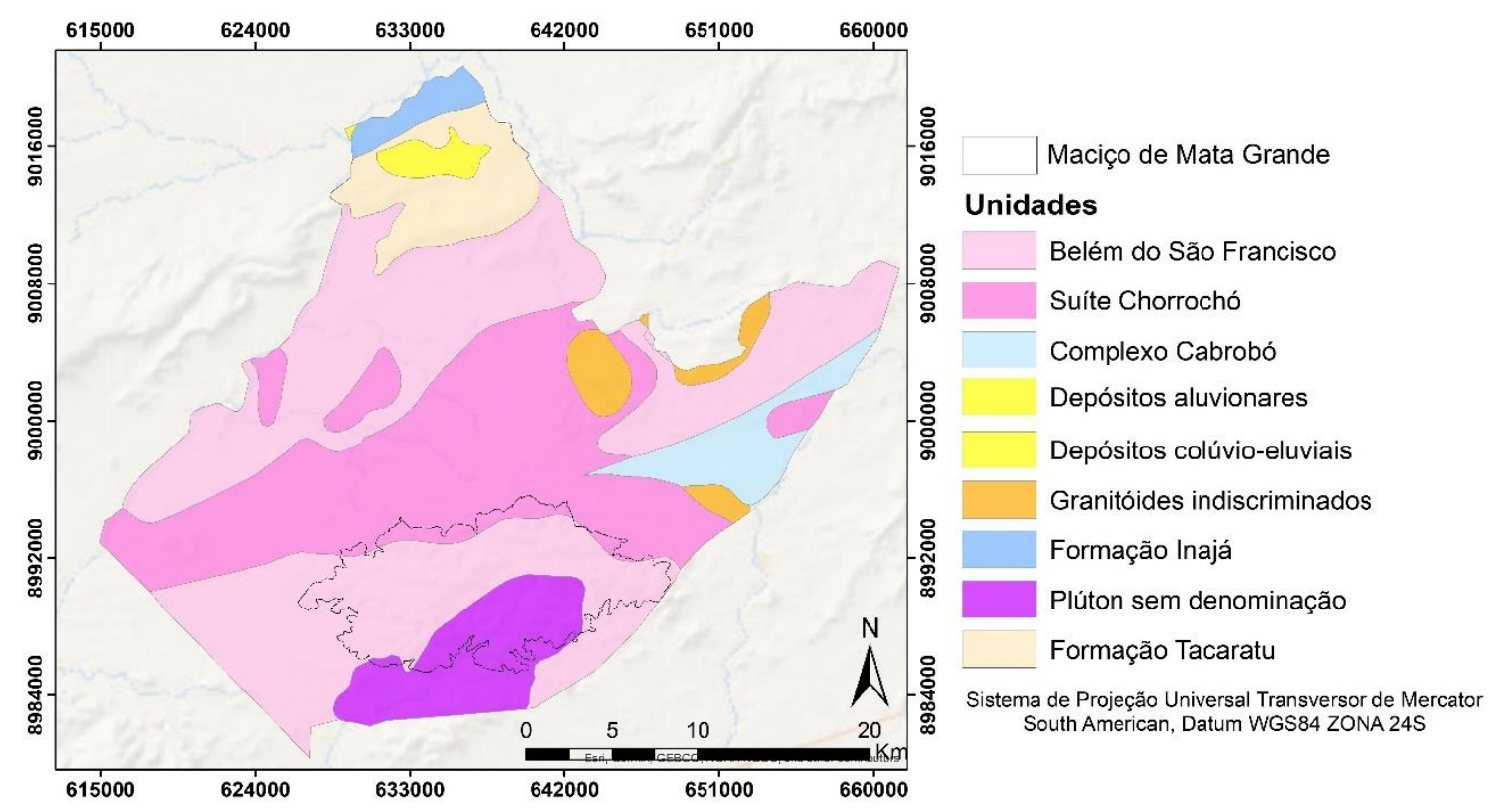

As feições do paleoproterozóico são representadas pelos plútons de Água Branca e Mata Grande, onde estão localizadas suas respectivas sedes municipais, 0 maciço de Água Branca estruturado em granitos e o de Mata Grande em quartzo sienito, quartzo álcali- feldspato sienito e quartzo monzonito. Do mesoproterozóico ocorrem principalmente feições estruturada em sienogranitos, gnaisses e migmatito intensamente fraturados. O paleozoico compreende as feições sedimentares da área estruturadas principalmente por arenitos. E por fim, o cenozoico, período mais recente, abrange os depósitos aluvionares compostos de areia, cascalho e níveis de argila e os depósitos colúvio-eluviais englobando sedimentos arenosos, arenoargilosos e conglomeráticos (CPRM, 2017).

\section{Geomorfologia}

A partir do mapeamento feito por Villanueva (2016) para o estado de Alagoas, o município de Mata Grande está inserido na Província Borborema, na unidade Depressão do São Francisco ou Depressão Sertaneja. Esta se delimita a leste com os tabuleiros costeiros e com a escarpa ocidental do planalto da 
Borborema, a norte e a sul esta unidade se estende ainda pelos estados de Pernambuco e Sergipe.

De acordo com a classificação proposta por Cavalcanti (2010), a geomorfologia do município de Mata Grande está definida como depressão sertaneja meridional em sua maior parte, caracterizada por pedimentos com e sem cobertura detrítica, ocorrência de inselbergs e o maciço, possuindo características fisiográficas diferentes do entorno, associado aos plútons neoproterozóicos. Além destas, destaca-se ainda o planalto do Jatobá a norte compondo um modelado cuestiforme e a presença de relevos residuais com morros testemunho e mesas.

Cabe ressaltar que estes autores propuseram mapeamentos regionais, utilizando dados de larga escala que compunham todo o Estado de Alagoas. No caso de Cavalcanti (op cit) houve um detalhamento do mapeamento em escala local e de detalhe para o município de Poço das Trincheiras, não reproduzindo esta mesma escala de análise para outras partes do Estado de Alagoas.

Metodologia

O mapeamento geomorfológico é uma ferramenta de indiscutível importância para o estudo das estruturas e dos processos atuantes no relevo ao longo do tempo, ou seja, contribuindo para a diferenciação e interpretação das formas de origem tectônica, das formadas pelas mudanças climáticas e por aquelas oriundas da ação antrópica. Sendo assim, Cavalcanti (2013), afirma que o conhecimento das morfoestruturas é necessário para a compreensão dos processos modeladores do relevo e suas formas resultantes na paisagem.

Segundo Amorim et al, (2015), o trabalho de cartografar a geomorfologia de um lugar deve ser apoiado em critérios de representação gráfica bem definidos, para que se possa otimizar a sua leitura e facilitar a interpretação dos fenômenos geomorfológicos. Deste modo, foi realizado o mapeamento geomorfológico morfoestrutural e morfoescultural na área do maciço de Mata Grande e seu entorno, tendo como base de sua metodologia as recomendações da UGI (União Geográfica Internacional), e sua Comissão de Mapeamento Geomorfológico baseada nas propostas de Demek (1972), onde se recomenda como parte incial do mapeamento a identificação das morfoestruturas. Para identificar as morfoestruturas, inicialmente foi realizada a reunião de informações bibliográficas e cartográficas de ordem geológica, geomorfológica, morfotectônica e de outros temas que possam revelar a distribuição das principais estruturas geológicas e seu comportamento deformacional recente (CAVALCANTI, 2013). 
Para o processamento de dados utilizou-se de imagens do sensor ALOS com resolução de $12,5 \mathrm{~m}$. O processamento de dados deu-se inicialmente com a extração das feições lineares, caracterizadas por Ecthebehere et al (2007) como indicadoras de descontinuidades estruturais. A metodologia indica o uso de sombreamento com iluminação nos Azimutes 45, $90^{\circ}$, 315 e $360^{\circ}$ e destaque dos segmentos lineares como, por exemplo, vales e cristas. Posteriormente, foi confeccionado um diagrama de rosetas para cada Azimute indicando em quais direções ocorrem as frequências dos lineamentos (CORRÊA \& FONSÊCA, 2010; MONTEIRO, 2010; OLIVEIRA et al 2019).

Em seguida ocorreu a análise da estrutura e geologia principalmente nos locais que se mostraram mais alterados pela tectônica. Associou-se isso a MDEs e a partir das diferentes texturas e formas que este modelo apresentou foi possível a classificação das morfoestruturas.

Seguindo as recomendações de Demek (1972), após o mapeamento das morfoestruturas, devem ser mapeadas as morfoesculturas. Utilizou-se também os dados ALOS PALSAR com resolução de 12,5m para aplicação de Modelos Digitais de Elevação (MDE), buscando mapear os elementos de morfometria, dados de declividade e rugosidade do relevo.

Outras ferramentas utilizadas para o mapeamento foram os dados de rugosidade e declividade. A metodologia utilizada foi a proposta de SAMPAIO \& AUGUSTIN (2014), que utiliza o ICR (índice de concentração de rugosidade), buscando mapear unidades homogêneas de dissecação do relevo além de dados da declividade do terreno para definir os padrões de cada feição. De acordo com os autores os valores pixel-a-pixel não são utilizados, como é feito em algumas análises bidimensionais do relevo, por exemplo, no uso de perfis topográficos. $O$ índice considera um relevo plano como sendo aquele onde os dados de declividade mais baixos se repetem, por exemplo.

Inicialmente ocorreu a transformação de um MDE em mapa de declividade calculada em porcentagem, utilizando a ferramenta Slope do ArcMap, em seguida os valores foram convertidos para um shapefile de pontos, onde permaneceram com os valores de declividade como atributos. Posteriormente o arquivo foi processado na ferramenta Kernel estimator que calcula uma área de análise em cada ponto que é definida como raio de Kernel, este raio pode ser definido a partir de uma escala local $\left(564 \mathrm{~m}\right.$ de raio ou $\left.1 \mathrm{Km}^{2}\right)$, ou global $\left(1128 \mathrm{~m}\right.$ de raio ou $\left.4 \mathrm{Km}^{2}\right)$. Os autores indicam o uso de um raio global para macro escalas de continentes ou 
bacias, o que não condiz com a área de análise desse trabalho, portanto foi escolhido o raio local para aplicação da ferramenta Kernel. O resultado obtido foi um arquivo matricial contendo os valores de ICR que podem ser de 0 a $\infty$ onde quanto maior for o índice, mais dissecado é o relevo. Para o ICR local, não existe um número exato de classes, pois isto varia de área para área, os autores aconselham ainda que sejam atribuídos nomes como baixo, alto, muito alto as classes do mapa de ICR.

Os modelos foram processados em ambiente GIS e a partir das diferentes texturas e formas permitiu visualizar os elementos referentes à estrutura e a morfografia da área.

\section{Resultados e discussões}

\section{Lineamentos}

A extração dos lineamentos mostrou que a maioria deles está nas áreas mais altas, atuantes como divisores de drenagem, possuindo uma certa homogeneidade na maioria dos azimutes de iluminação. Para os azimutes de $90^{\circ}, 315^{\circ}$ e $360^{\circ}$ os lineamentos de relevo apresentaram direção preferencial NE-SW e para o azimute de $45^{\circ}$ uma direção preferencial NW-SE (Figura 3).

Figura 3- Lineamentos de relevo nos azimutes $45^{\circ}, 90^{\circ}, 315^{\circ}$ e $360^{\circ}$; ISZ - Zona de

Cisalhamento Itaíba

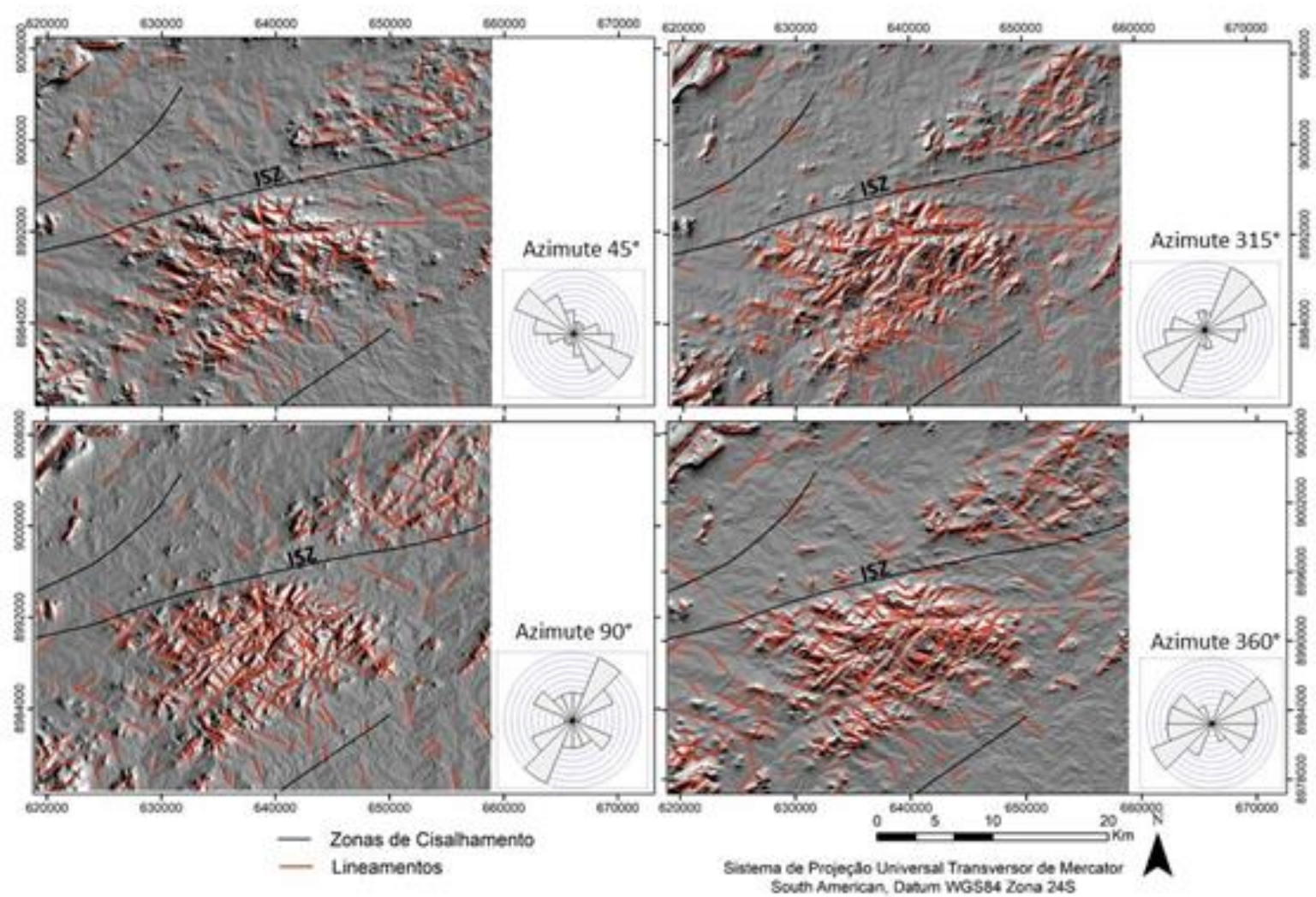


As áreas que concentram a maioria dos lineamentos se encontram entre a Zona de Cisalhamento Itaíba e uma Zona de Cisalhamento indiscriminada, sendo as duas de regime transcorrente dextral e com um trend preferencial de NE-SW (SILVA FILHO et al, 2016), o que sugere que os lineamentos da região podem estar associados à estas estruturas reativadas.

É importante mencionar que parte destas áreas são constituídas por plútons de composição litológica granítica e sienítica o que indica uma maior resistência litológica. Há também a ocorrência de baixo grau de foliação que é atribuído pela CPRM (2016) à alta ocorrência de camadas milonitizadas e migmatizadas associadas às Zonas de Cisalhamento. Portanto é sugerível uma associação de controles estruturais e litológicos na faixa de áreas altas correspondente ao maciço de Mata Grande e adjacências.

Quanto ao azimute de iluminação $45^{\circ}$, este possui uma direção preferencial de NW-SE, o que sugere que estes lineamentos estão ligados às drenagens em gargalo presentes nas bordas das áreas elevadas, sobretudo no plúton de Mata Grande.

\section{Morfometria}

Os resultados obtidos com os dados de ICR e declividade, foram muito próximos (Figura a), os locais mais dissecados e mais declivosos concentram-se nas áreas mais altas, como era de se esperar. Porém há ainda a presença de valores mais acentuados a SW e SE de Mata Grande indicando que apesar de ser um relevo rebaixado ainda possui áreas bastante dissecadas com ICR médio, assim como há uma presença maior de unidades suave onduladas e onduladas. A partir desses dados é possível supor que há um trabalhamento maior nessas áreas. $\mathrm{Na}$ porção a N e NW de Mata Grande, há um relevo mais homogêneo, com poucos indícios de dissecação indicando que essas porções já foram arrasadas. 
Figura 4- Mapa de Rugosidade e de Declividade

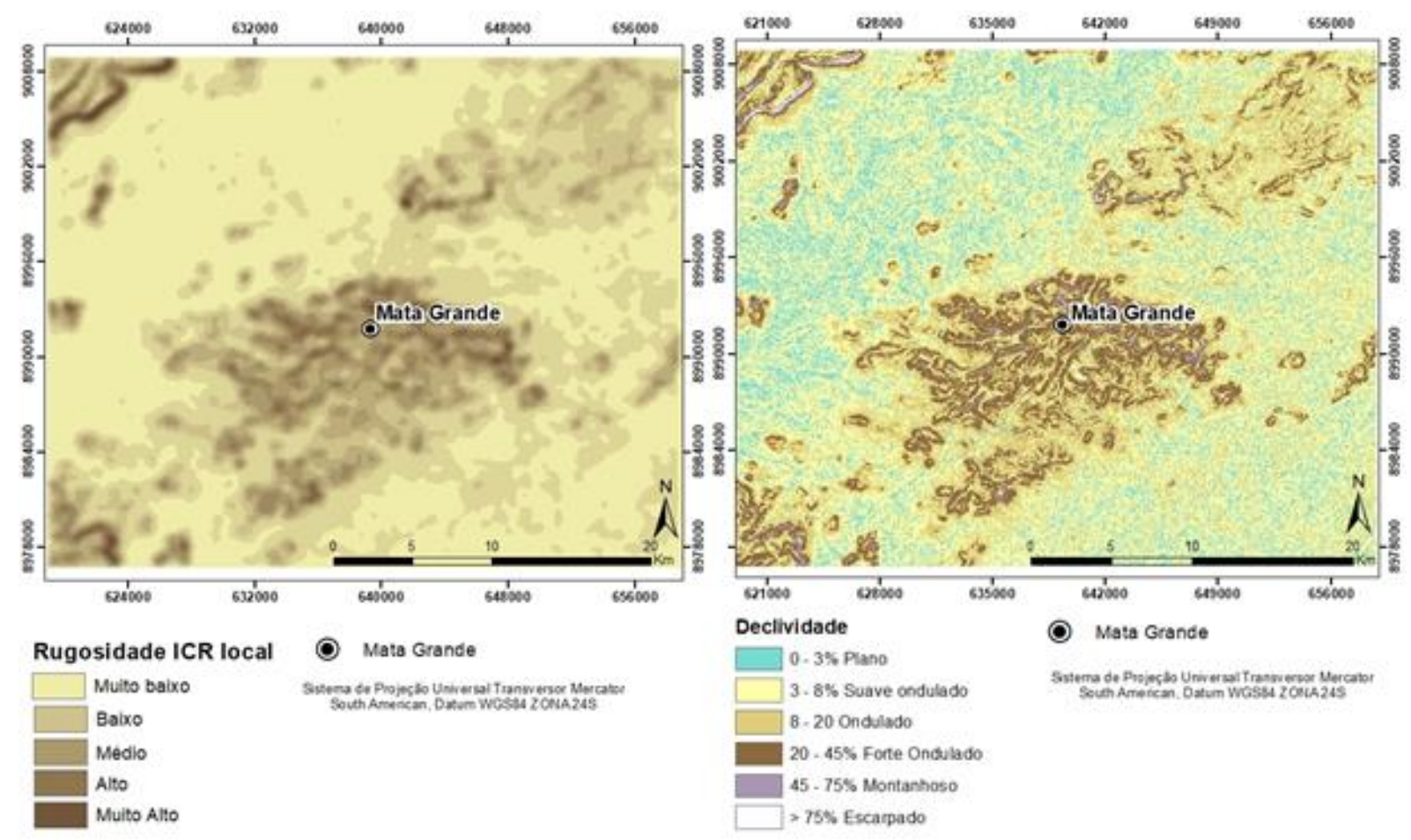

Unidades geomorfológicas

Morfoestruturas

A partir da associação entre estrutura, litologia e altimetria foram definidas as feições morfoestruturais da área. O mapeamento mostrou inicialmente que a área do maciço de Mata Grande é um divisor de três bacias hidrográficas, a do Rio Moxotó que nasce em Pernambuco, a do Rio Capiá que também tem cabeceiras em Pernambuco e a do Riacho Talhada que tem sua cabeceira no próprio maciço de Mata Grande. Ao todo foram identificadas 11 unidades morfoestruturais (Figura 5).

Figura 5- Mapa das unidades morfoestruturais 


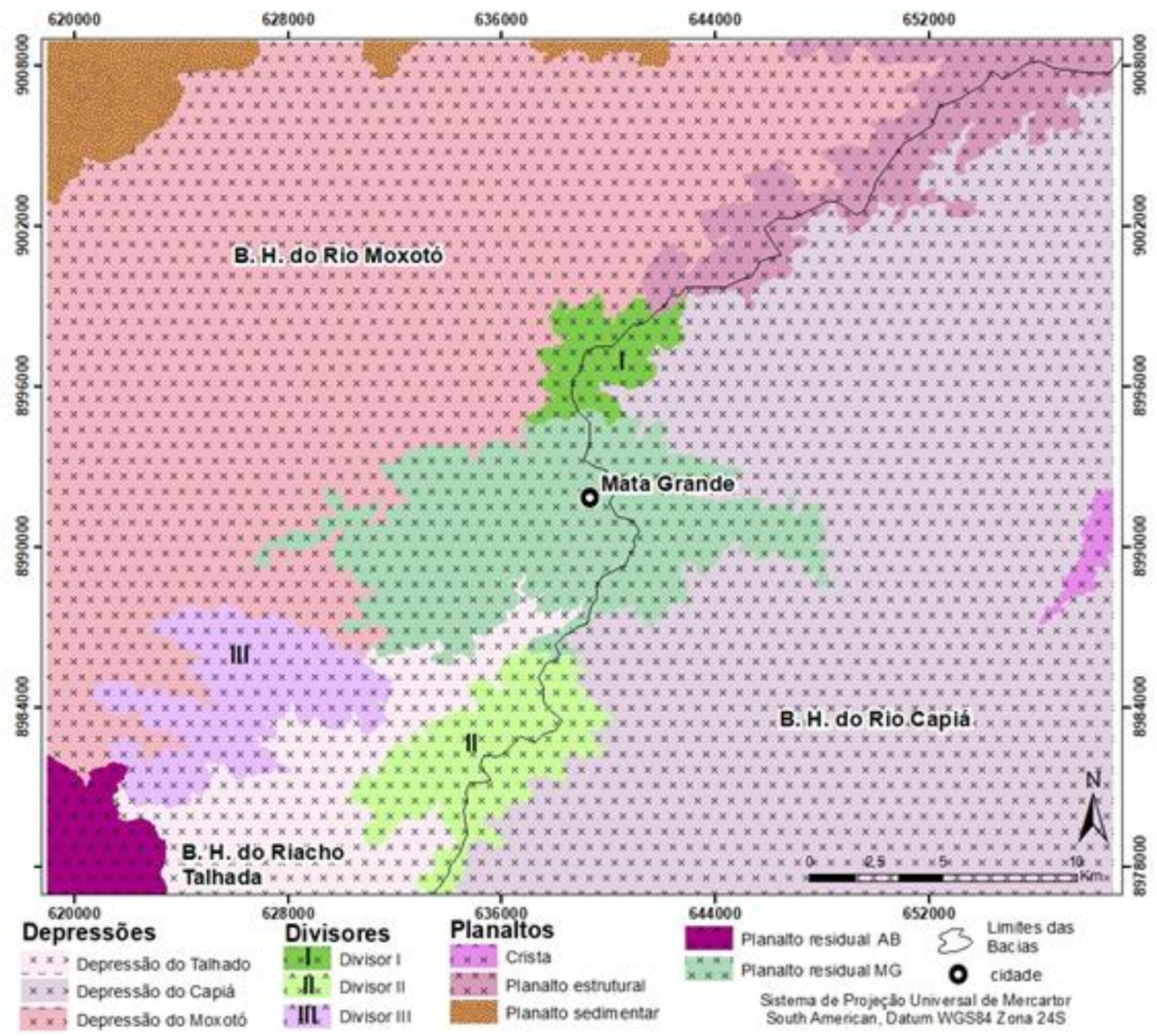

- Depressões

Ao todo foram identificadas 3 unidades de depressões referentes as bacias no limite estabelecido. A primeira foi a Depressão do Moxotó, esta constitui-se como uma depressão periférica, é o limite entre o relevo homoclinal da bacia do TucanoJatobá e da formação Tacaratu com os maciços cristalinos geologicamente caracterizados como plútons de Mata Grande (Figura 5), possuindo cota mínima em 280m. A litologia predominante da área é de ortognaisses em sua maioria, mas ainda conta com metadioritos, metagranitos e metamonzodiorito, todas na subclasse dos metamorfismos regionais.

A segunda foi a depressão do Capiá, a leste do maciço (Figura 5), possuindo cota mínima em 60m, quando encontra o Rio São Francisco, fora do recorte estabelecido. A litologia é de ortognaisses e migmatitos mais próximo do maciço e de biotita na medida que se distancia dele. Como a do Moxotó, tem a litologia na classe dos metamorfismos regionais.

A terceira é a Depressão do Talhada, possui cota mínima em $140 \mathrm{~m}$ ao encontrar o Rio São Francisco, sua litologia predominante é de gnaisses e 
migmatitos na área do recorte. Todas as depressões possuem em sua composição rochas do Complexo Belém de São Francisco e Complexo Cabrobó, isto explica a origem de suas litologias, em grande parte metamorfizada.

- Planaltos

A primeira unidade de planalto identificada no mapeamento foi a de um planalto sedimentar homoclinal de litologia pertencente à bacia do Tucano-jatobá e à formação Tacaratu (Figura 5), com presença de arenitos e conglomerados, possuindo uma cota mínima de $400 \mathrm{~m}$ e tendo o rio Moxotó promovendo uma superimposição de drenagem.

A segunda unidade de planalto é um maciço estrutural constituinte do Planalto da Borborema (Figura 5), mais precisamente do Domínio Pernambuco Alagoas (CORRÊA et al, 2010). A litologia é composta de granito, sienogranito e migmatito. Atua como uma das cabeceiras dos afluentes do Rio Capiá.

Os planaltos residuais formam a terceira unidade de planaltos, são destacados na paisagem e atuam como divisores de drenagem. Dois se destacam, o de Mata Grande (MG) e o maciço de Água Branca (AB), a SW de Mata Grande, suas cotas mínimas são de $500 \mathrm{~m}$, porém os topos estão a $800 \mathrm{~m}$ em Mata Grande e a aproximadamente $650 \mathrm{~m}$ em Água Branca. A litologia do primeiro (MG) é composta quase que completamente por sienito. $O$ segundo $(A B)$ possui litologia de granitos em diferentes tipos de decomposição.

Ainda no grupo dos planaltos residuais, foi identificada uma crista de metagranito a sudeste de Mata Grande, pertencente a Suíte Chorrochó, com uma cota mínima de 380m.

\section{- Divisores}

Os planaltos atuam como divisores das bacias hidrográficas da área. Além deles foram identificadas 3 unidades de divisores que possuem estruturas cristalinas, mas que não são resistentes o suficiente e estão passando por processo de degradação, o que os classifica como divisores rebaixados (Figura 5). No mapeamento foram identificadas três unidades de divisores rebaixados, que separam não só as bacias, mas também os maciços do Planalto da Borborema.

Todos os divisores foram identificados com cota mínima de $400 \mathrm{~m}$. Nos divisores entre as Bacias Hidrográficas do Rio Capiá e do Rio Moxotó (Divisor I), tem-se cota máxima de $480 \mathrm{~m}$ e estão estruturados em metadioritos da Suíte Chorrochó. No divisor da bacia do Talhada com a do Capiá (Divisor II) tem-se um só 
grande corpo atingindo cota máxima de $600 \mathrm{~m}$ estruturado em sienito e quartzo sienito, tal como o plúton de Mata Grande. Nos divisores entre as bacias do Talhada e do Moxotó (Divisor III) encontram-se cotas máximas de 500m, sendo eles estruturados em ortognaisses do Complexo Belém de São Francisco.

Morfoesculturas

As morfoestruturas foram separadas e associadas aos dados de declividade, rugosidade e altimetria para estabelecimento das morfoesculturas, que são feições mais recentes e modeladas como resultado da ação clima sobre estrutura. As unidades morfoesculturais foram divididas em dois grupos (Formas Agradacionais e Formas Erosionais) de acordo com a predominância dos processos atuantes na sua formação (Figura 6).

Figura 6- Mapa com as unidades morfoesculturais 


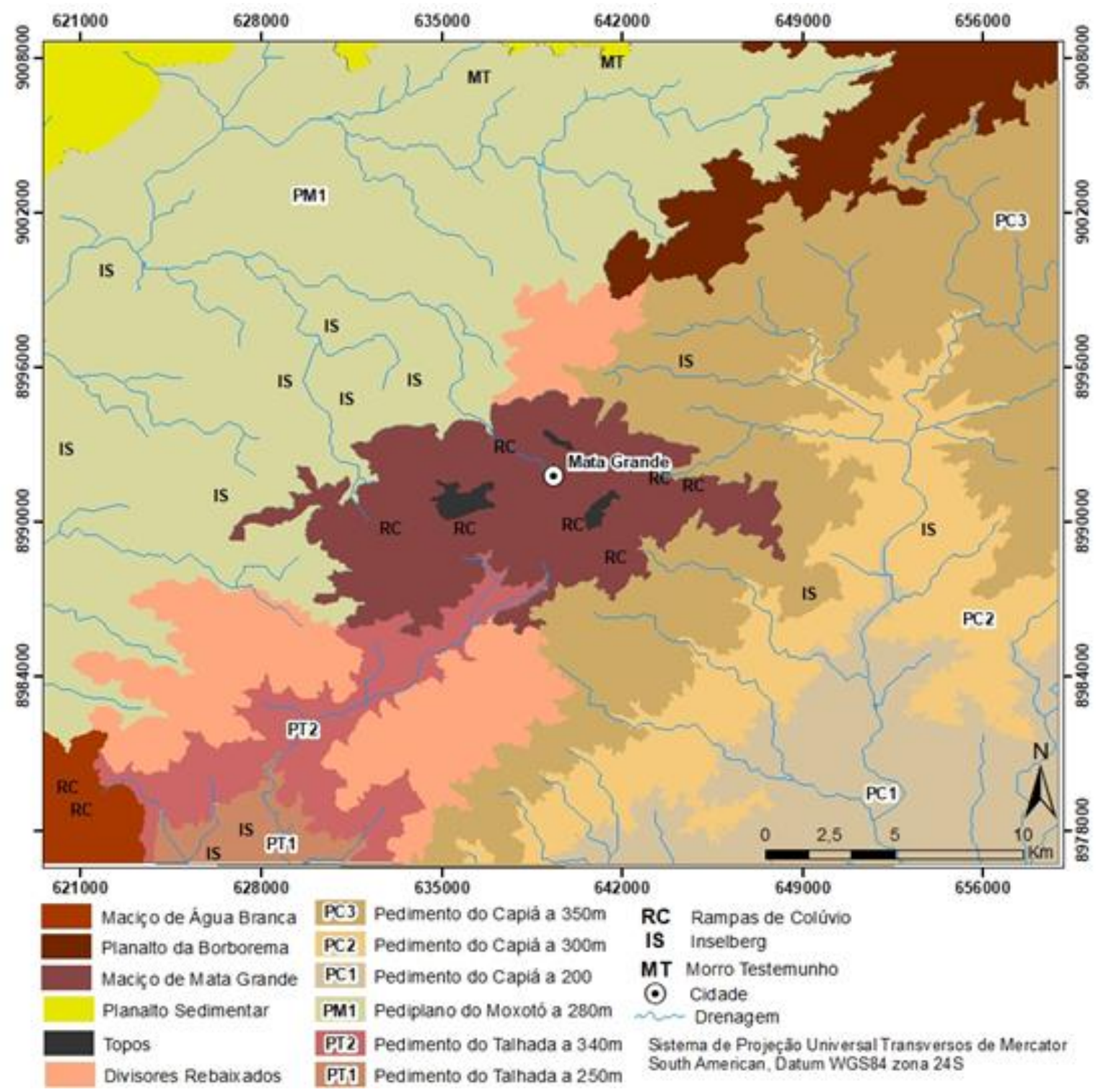

- Formas Agradacionais

As rampas de colúvio

Dentro das unidades morfoesculturais agradacionais, foi observada apenas a unidade das Rampas de Colúvio, a maioria das rampas está localizada dentro de alvéolos suspensos e entre a média e a alta encosta, sendo a espessura das mais variadas indo de $40 \mathrm{~cm}$ até $12 \mathrm{~m}$. Apresentam-se ainda tanto individualmente, ou seja, uma única rampa, quanto em grande quantidade o que é chamado de complexo de rampas de colúvio.

- Formas Erosionais

Pedimentos e Pediplano

Os pedimentos constituem unidades erosivas em forma de rampas que vão dos canais até a encosta. A coalescência de dois pedimentos forma um pediplano. Os pedimentos e o pediplano foram mapeados separadamente em cada bacia hidrográfica contida no recorte, assim foram encontrados diferentes níveis dentro de 
cada uma. A partir dos dados obtidos, principalmente de declividade, geologia e altimetria, essas diferenças ficaram mais visíveis.

Para a bacia hidrográfica do Riacho do Talhada foram encontrados dois níveis de pedimentos sendo o primeiro nomeado PT2 (Figura 6), que está a uma cota mínima de 340m e apresenta-se com o maior nível de dissecação. O segundo PT1 possui cota mínima de 250m.

$\mathrm{Na}$ Bacia Hidrográfica do Rio Capiá foram identificados 3 níveis de pedimentos (Figura 6), o primeiro PC3 possui cota mínima de 350m, o segundo PC2 com cota mínima de $300 \mathrm{~m}$ e o terceiro PC1 com cota mínima de 200m. Porém a depender da escala e do dado, estas diferenças altimétricas de 50m tornam-se imperceptíveis, ou até mesmo ignoradas visto que para grandes escalas não ficariam tão expressivas.

Para a Bacia Hidrográfica do Rio Moxotó foi identificada apenas uma grande rampa, ou pediplano, com cota mínima de 280m (Figura 6). A estrutura do Tucano está associada aos soerguimentos cretácicos ocorridos durante as reativações pós Godwana. Ou seja, ocorreu um soerguimento na Bacia Hidrográfica do Rio Moxotó que pode explicar o fato de, nesta área, apesar das margens possuírem extensões muito diferentes ( $1 \mathrm{~km}$ na margem direita e $14 \mathrm{~km}$ na margem esquerda), existir o mesmo nível altimétrico, formando o Pediplano do Moxotó.

Quanto à dissecação, o pedimento PT2 localizado na Bacia do Talhada apresentou dissecação mais forte, próximo a sua cabeceira, os pedimentos PC3 e PC2 apresentaram uma dissecação mais amena e os demais não apresentam grandes dissecações.

\section{Topos}

No recorte só foi possível identificar o topo do maciço de Mata Grande (Figura 6), já que este não abrange o topo das outras estruturas. Neste maciço o topo encontra-se acima de $750 \mathrm{~m}$ e chega até $800 \mathrm{~m}$. Estas áreas estão localizadas as margens de uma região mais rebaixada onde está o perímetro urbano e se caracteriza como um provável pedimento embutido, porém não foi inserido no mapeamento, pois necessita de análises fora do escopo desse trabalho. Os topos apresentam de pouquíssima a nenhuma cobertura detrítica, porém possuem uma suavização o que os caracteriza como topos convexos.

Inselbergs e Morro Testemunho

Os inselbergs estão concentrados em maioria na bacia do Moxotó (Figura 6), possuem uma cota máxima média de 500m, estruturados em granitos. 
O morro testemunho na porção Norte do mapeamento (Figura 6), apresenta um topo plano e ainda está muito próximo do limite da Cuesta, possui um topo em $500 \mathrm{~m}$ e é composto por arenito.

\section{Considerações Finais}

A metodologia proposta para o mapeamento de unidades morfoestruturais se mostrou bastante eficaz, foi possível identificar ao todo 11 unidades de morfoestruturas nas adjacências do maciço de Mata Grande. O uso dos lineamentos e das características geológicas e estruturais foi essencial na caracterização, delimitação e interpretação dessas unidades. Quanto às unidades morfoesculturais, a metodologia também se mostrou satisfatória para o nível de detalhe proposto no mapeamento, visto que a escala não permite um aporte maior de detalhes.

Os elementos utilizados neste mapeamento foram significativos, deixando explícitas as peculiaridades da área tais como a condição de divisores de drenagem e em especial ao Maciço de Mata Grande, divisor de 3 bacias hidrográficas. A região mostrou-se ainda com interessante contexto geomorfológico, pois contempla feições muito próximas nos aspectos espacial e temporal, porém suas rochas são de épocas diferentes. Por exemplo, os plútons que estruturam os maciços cristalinos são provenientes de resfriamentos do magma que datam do paleoproterozóico e os arenitos que estruturam o planalto homoclinal, são ligados a sucessivos soerguimentos cretácicos, estando as duas unidades com cotas altimétricas muito semelhantes.

Esse tipo de metodologia é essencial principalmente em área como os brejos de altitude que dispõem de condições ambientais especiais, contribuindo para a gestão de ocupação de áreas e uso da terra, assim como também dá suporte a estudos no âmbito da geomorfologia. No caso do recorte mapeado, os divisores constituem as cabeceiras de drenagem em sua maioria com vertentes côncavas, passíveis de movimentos de massa, condição subentendida através da quantidade de rampas de colúvio na alta encosta de Mata Grande e, que, portanto, precisam ter um manejo controlado. Essas rampas podem ser explicadas pela condição ambiental, sobretudo a climatológica diferenciada da região que permite 0 desenvolvimento de mantos de intemperismo que, posteriormente, se tornaram colúvios formando as rampas. 


\section{REFERÊNCIAS}

AMORIM, R. F. et al . Cartografia de relevo aplicado à bacia do riacho Bruscas, maciço da serra da Baixa Verde (PE/PB), nordeste do Brasil. Revista de Geociências do Nordeste, v. 01, p. 1-20, 2015.

CAVALCANTI, L.C. Geossistemas no estado de Alagoas: uma contribuição aos estudos da natureza em geografia. Dissertação (Mestrado). Universidade Federal de Pernambuco. Centro de Filosofia e Ciências Humanas. 2010.

CAVALCANTI, L. C. Da descrição de áreas à teoria dos Geossistemas: uma abordagem epistemológica sobre sínteses naturalistas. Tese (Doutorado). Universidade Federal de Pernambuco. Centro de Filosofia e Ciências Humanas. 2013.

CORRÊA, A. C. B. et al. MEGAGEOMORFOLOGIA E MORFOESTRUTURA DO PLANALTO DA BORBOREMA. Revista do Instituto Geológico, São Paulo, 31 (1/2), 35-52, 2010.

CORRÊA, A. C. B; FONSECA, D. N. LINEAMENTOS DE DRENAGEM E DE RELEVO COMO SUBSÍDIO PARA A CARACTERIZAÇÃO MORFOESTRUTURAL E REATIVAÇÕES NEOTECTÔNICAS DA ÁREA DA BACIA DO RIO PRETO, SERRA DO ESPINHAÇO MERIDIONAL - MG. Revista de Geografia. Recife: UFPE - DCG/NAPA, v. especial VIII SINAGEO, n. 1, set. 2010.

CPRM. Geologia e recursos minerais do estado de Alagoas. Recife, 407p. 2016.

CPRM. Projeto cadastro de fontes de abastecimento por água subterrânea. Disponível em:

http://rigeo.cprm.gov.br/xmlui/bitstream/handle/doc/15289/rel_cadastros_mata_grande.\%20p df?sequence=1. Acesso em: 13 de agosto de 2017.

DEMEK J. (ed) Manual of detailed geomorphological mapping. Praga, IGU, Comm Geomorph. Surv. Mapping, 1972.

ETCHEBEHERE, M. L. C; SAAD, A. R; FULFARO, V. J. ANALISE DE BACIA APLICADA À PROSPECÇÃO DE ÁGUA SUBTERRÂNEA NO PLANALTO OCIDENTAL PAULISTA, SÃO PAULO. São Paulo, UNESP, Geociências, v - 26, n3, p 229 - 247, 2007.

MONTEIRO, K.A. Superfícies de aplainamento e morfogênese da bacia do Rio Tracunhaém, Pernambuco. Dissertação (Mestrado). Universidade Federal de Pernambuco, Programa de Pós-Graduação em Geografia. Recife. 2010.

OLIVEIRA, M. A. et al. ANÁLISE DE LINEAMENTOS ESTRUTURAIS NA BACIA HIDROGRÁFICA DO RIO PIAUÍ, SE/BA. In: Anais do XVIII Simpósio Brasileiro de Geografia Física Aplicada. Fortaleza, 2019.

SAMPAIO, T. V. M; AUGUSTIN, C. H. R. R. ÍNDICE DE CONCENTRAÇÃO DA RUGOSIDADE: UMA NOVA PROPOSTA METODOLÓGICA PARA O MAPEAMENTO E QUANTIFICAÇÃO DA DISSECAÇÃO DO RELEVO COMO SUBSÍDIO A CARTOGRAFIA GEOMORFOLÓGICA. Revista Brasileira de Geomorfologia, São Paulo, v.15, n.1, (JanMar) p.47-60, 2014.

SILVA FILHO, A. F; GUIMARÃES, I. P; SANTOS, L; ARMSTROG, R; VAN SCHMUS, W. $\mathrm{R}$. Geochemistry, U-Pb geochronology, Sm-Nd and $\mathrm{O}$ isotopes of ca. $50 \mathrm{Ma}$ long Ediacaran High-K Syn-Collisional Magmatism in the Pernambuco Alagoas Domain, Borborema Province, NE Brazil. Journal of South American Earth Sciences. 2015.

VILLANUEVA, T. C. B. Geodiversidade do estado de Alagoas. Salvador: CPRM, 2016. $165 p$. 


\section{NOTAS DE AUTOR}

\section{CONTRIBUIÇÃO DE AUTORIA}

Laís Susana de Souza Gois - Coleta de dados, Análise de dados, Elaboração do manuscrito.

Nivaneide Alves de Melo Falcão - Coleta de dados Participação ativa da discussão dos resultados; Revisão e aprovação da versão final do trabalho.

Kleython de Araújo Monteiro - Coleta de dados Participação ativa da discussão dos resultados; Revisão e aprovação da versão final do trabalho

\section{FINANCIAMENTO}

Bolsa de Mestrado acadêmico concedida pela Coordenação de Aperfeiçoamento de Pessoal de Nível Superior CAPES;

Auxílio Financeiro na forma de diárias concedido pelo Comitê da Bacia Hidrográfica do Rio São Francisco através da Agência Peixe Vivo.

\section{CONSENTIMENTO DE USO DE IMAGEM}

Não se aplica

\section{APROVAÇÃO DE COMITÊ DE ÉTICA EM PESQUISA}

Não se aplica

\section{CONFLITO DE INTERESSES}

Não se aplica

\section{LICENÇA DE USO}

Este artigo está licenciado sob a Licença Creative Commons CC-BY. Com essa licença você pode compartilhar, adaptar, criar para qualquer fim, desde que atribua a autoria da obra.

\section{HISTÓRICO}

Recebido em: 04-06-2020

Aprovado em: 15-04-2021 